\title{
miR-15a inhibits cell apoptosis and inflammation in a temporal lobe epilepsy model by downregulating GFAP
}

\author{
YUEHUI FAN ${ }^{1}$, WEIPING WANG ${ }^{1}$, WEIFENG $\mathrm{LI}^{2}$ and XIANJUN $\mathrm{LI}^{2}$ \\ ${ }^{1}$ Department of Key Laboratory of Neurology of Hebei Province, The Second Hospital of Hebei Medical University, \\ Shijiazhuang, Hebei 050000; ${ }^{2}$ Department of Neurology, The First Hospital of Shijiazhuang, \\ Shijiazhuang, Hebei 050011, P.R. China
}

Received August 31, 2019; Accepted April 22, 2020

DOI: $10.3892 / \mathrm{mmr} .2020 .11388$

\begin{abstract}
Temporal lobe epilepsy (TLE) is a type of epilepsy, which is associated with high morbidity and recurrence rates, and is also difficult to treat. Therefore, it is important to identify novel treatments for TLE. In recent years, with the development of molecular therapies, the regulatory mechanisms and networks of microRNAs (miRNAs/miRs) have become areas of great interest in disease research. The present study aimed to determine a potential novel therapeutic target for the treatment of TLE by identifying differentially expressed miRNAs. The function of miR-15a was verified in vivo and in vitro by constructing a rat epilepsy model and using hippocampal neurons treated with $\mathrm{Mg}^{2+}$-free medium, respectively. The mRNA expression levels of miR-15a, glial fibrillary acidic protein (GFAP), interleukin (IL)-1 $\beta$, IL-6 and tumor necrosis factor $\alpha$ (TNF- $\alpha$ ) were analyzed using reverse transcription-quantitative PCR. Furthermore, the protein expression levels of GFAP were determined using western blotting. TUNEL and flow cytometry assays were used to detect the levels of cell apoptosis both in vitro and in vivo, respectively. In addition, dual-luciferase reporter and RNA immunoprecipitation (RIP) assays were performed to determine the relationship between miR-15a and GFAP. The results of the present study suggested that the expression levels of miR-15a were downregulated in TLE tissues and epileptic cells. It was also discovered that the upregulated expression levels of miR-15a significantly inhibited the rate of apoptosis in epileptic cells, in addition to the expression levels of IL-1 $\beta$, IL- 6 and TNF- $\alpha$ in vitro and in vivo. Moreover, the dual-luciferase reporter and RIP assays results demonstrated that miR-15a directly targeted GFAP in hippocampal neurons.
\end{abstract}

Correspondence to: Mrs. Weiping Wang, Department of Key Laboratory of Neurology of Hebei Province, The Second Hospital of Hebei Medical University, 215 West Heping Road, Shijiazhuang, Hebei 050000, P.R. China

E-mail: dspqxe@163.com

Key words: temporal lobe epilepsy, microRNA-15a, glial fibrillary acidic protein, cell apoptosis, inflammation
Rescue experiments indicated that increasing the expression levels of GFAP effectively attenuated the inhibitory effects of the high expression levels of miR-15a on apoptosis and inflammation. In conclusion, the results of the present study suggested that the upregulation of miR-15a may inhibit cell apoptosis and inflammation in TLE by targeting GFAP, thus providing a potential therapeutic target for the treatment of TLE.

\section{Introduction}

Epilepsy is a complicated neurological condition that reoccurs in patients (1). Temporal lobe epilepsy (TLE), one of the most common types of epileptic seizures, is a chronic neurological disorder that originates from the temporal lobe of the brain (2). The etiology of TLE is complicated and the prevalence of the disease is high, with an incidence rate of 61.4 in 100,000 individuals (95\% CI 50.7-74.4) (3). Furthermore, $~ 1 / 3$ of patients are not effectively treated following the use of the common drugs, such as carbamazepine and Phenytoin sodium $(1,4,5)$. The intractable nature of epilepsy renders both the treatment and rehabilitation of the disorder difficult (6). Therefore, further studies are required to increase the understanding of the pathogenesis of epilepsy, and to discover effective therapeutic targets and molecular therapies for the treatment of TLE.

MicroRNAs (miRNAs/miRs), which are found in eukaryotes, area class of endogenous, highly conserved non-coding small RNAs with regulatory functions (7). miRNAs identify target genes by base pairing, which results in the degradation or the inhibition of translation of the target gene $(8,9)$. Moreover, miRNAs have been reported to be involved in various stages of biological growth and development, especially in cell growth and tissue differentiation, which are closely related to several types of disease, such as melanoma and chronic lymphocytic leukemia (10-14). Previous studies have reported that multiple miRNAs are differentially expressed in the central nervous system, suggesting that miRNAs may be involved in the development of neurological pathology, including TLE (15-20). However, the specific regulatory mechanisms of these miRNAs require further research. miR-15a is a conserved miRNA, which was discovered to participate in cell progression in numerous types of cancer, 
including thyroid cancer and prostate cancer $(21,22)$, in addition to epilepsy $(23,24)$. Furthermore, miR-15a has been suggested to serve as a biomarker, as low expression levels of miR-15a were previously reported in epilepsy $(25,26)$. However, the function of miR-15a in epilepsy is not fully understood.

Glial fibrillary acidic protein (GFAP) is a marker of astrocyte activation and it is mainly distributed in astrocytes of the central nervous system $(27,28)$. Moreover, GFAP has been discovered to be closely related to cell progression and inflammation in numerous types of neurological disease $(29,30)$. For example, it was discovered that GFAP was highly expressed in epilepsy, and increasing its expression levels aggravated the neuroinflammatory response $(31,32)$.

To further examine whether miR-15a serves a role in TLE, cell lines overexpressing miR-15a were constructed via cell transfection. In addition, GFAP was predicted to be a target mRNA of miR-15a using microT-CDS, followed by validation using dual-luciferase reporter and RNA immunoprecipitation (RIP) assays. Therefore, the present study hypothesized that miR-15a may be associated with TLE by targeting GFAP.

\section{Materials and methods}

Patients studies. Temporal lobe cortical tissues $(\mathrm{n}=18)$ were removed from drug-resistant patients with TLE. Control tissues from healthy temporal neocortical tissues $(n=18)$ were obtained during the autopsy of patients who had no history of seizures or other neurological diseases in The Second Hospital of Hebei Medical University (Shijiazhuang, China) between March 2016 and August 2018. The age of the patients ranged from $25.7 \pm 12.4$ years, including ten females and 26 males. The inclusion criteria were as follows: i) Patients who were diagnosed with TLE via pathological examination; ii) patients who were diagnosed and treated for the first time; and iii) patients who willing to join the study. The exclusion criteria were: i) Patients with multiple diseases; and ii) patients who received treatment within 90 days before admission. All samples were stored at $-80^{\circ} \mathrm{C}$. The study was approved by the Ethics Committee of The Second Hospital of Hebei Medical University and all patients provided written, informed consent.

Construction of the epilepsy animal model. To simulate the seizure process, the present study constructed a pilocarpine-induced animal model with similar seizure characteristics to human TLE to study the mechanisms of TLE (33). All animal experiments were approved by the Ethics Committee of The Second Hospital of Hebei Medical University (Shijiazhuang, China). In total, $32 \mathrm{BALB} / \mathrm{c}$ female Wistar rats (age, 8-10 weeks; weight, 200 g; Experimental Animal Centre of the Academy of Military Medical Sciences, Beijing, China) were randomly divided into four groups ( 8 rats in each group): Normal group, epilepsy group, epilepsy $+\mathrm{LV}$-miR-negative control (NC; 5'-UUCUCCGAACGUGUCACGUUU-3') group (hippocampi transfected with miR-NC; final concentration $50 \mu \mathrm{M}$ ) and epilepsy+LV-miR-15a group [hippocampi transfected with miR-15a mimics (miR-15a: 5'-UAGCAGCACA UAAUGGUUU-3'), final concentration $50 \mu \mathrm{M}$ ]. Transfected LV-miR-NC or LV-miR-15a were subcutaneously injected into the hippocampi of anesthetized rats. LV-miR-NC and LV-miR-15a were obtained from Shanghai GenePharma Co., Ltd. Rats were housed at room temperature of $22-25^{\circ} \mathrm{C}$, with a relative humidity of 50-60\%, with a 12 -h light/dark cycle. The food intake of the rats was $\sim 10 \mathrm{~g}$ per $100 \mathrm{~g}$ body weight, and the water intake was $10-15 \mathrm{ml}$ per $100 \mathrm{~g}$ body weight. Rats in the epilepsy, epilepsy + LV-miR-NC and epilepsy + LV-miR-15a groups were intraperitoneally injected with lithium chloride (127 mg/kg; Sigma-Aldrich; Merck KGaA). Then, $18 \mathrm{~h}$ later, pilocarpine $(127 \mathrm{mg} / \mathrm{kg}$; Sigma-Aldrich; Merck KGaA) was repeatedly injected intraperitoneally every 30 min until the rats had seizures with tonic-clonic (head and face clonic, limb clonic) using an electroencephalogram and observation. Rats in the normal group were intraperitoneally injected with an equivalent volume of physiological saline. The epileptic seizure was terminated after an epileptic state that lasted for $1 \mathrm{~h}$. After $24 \mathrm{~h}, 10 \%$ chloral hydrate $(300 \mathrm{mg} / \mathrm{kg})$ was used to anesthetize the rats at $5 \mathrm{ml} / \mathrm{kg}$ intraperitoneally and then the ratswere euthanisedby cervial disclocation. The brain was removed and the tissue was isolated from the rat hippocampus on iced saline and stored at $-80^{\circ} \mathrm{C}$.

Cell culture and transfection. Rat hippocampus neurons were obtained from rat hippocampus tissue. Briefly, Rat hippocampus tissue from the removed brain was dissected and placed on a cell plate $\left(1 \times 10^{5} / \mathrm{ml}\right)$ with neurobasal medium (neurobasal/B27; Thermo Fisher Scientific, Inc.), containing 2\% BC7 (Gibco; Thermo Fisher Scientific, Inc.), and 10\% FBS (Gibco; Thermo Fisher Scientific, Inc.) cultured with 5\% dihydrazide, at $37^{\circ} \mathrm{C}$ in a humid environment. After plating, $5 \mu \mathrm{M}$ cytosine arabinoside (Sigma-Aldrich; Merck KGaA) was used to inhibit astrocyte proliferation in hippocampal neurons at $37^{\circ} \mathrm{C}$ for $48 \mathrm{~h}$. The medium was replaced every 2 days. After a 2-week in vitro culture, epilepsy induction was performed as followed. Briefly, the original medium was replaced with a $\mathrm{Mg}^{2+}$-free medium (Sigma-Aldrich; Merck KGaA) containing $2.5 \mathrm{mM} \mathrm{KCl}, 145 \mathrm{mM} \mathrm{NaCl}, 2 \mathrm{mM} \mathrm{CaCl}{ }_{2}, 10 \mathrm{mM}$ HEPES, $10 \mathrm{mM}$ glucose and $0.002 \mathrm{mM}$ glycine and the epileptic neuron cells were cultured for 6 days at $37^{\circ} \mathrm{C}$. Subsequently, the neurons were cultured at $37^{\circ} \mathrm{C}$ in liquid $\mathrm{Mg}^{2+}$-free medium for $3 \mathrm{~h}$. Then, neuronal cells were transferred to the conventional neurobasal/B27 medium for culture at $37^{\circ} \mathrm{C}$. Control (con) cells were cultured in neurobasal/B27 medium under the same incubation conditions.

miR-15a and miR-NC, miR-15a inhibitors (anti-miR-15, 5'-AAACCAUUAUGUGCUGCUA-3') and anti-miR-NC (5'-CAGUACUUUUGUGUAGUACAA-3'), as well as pcDNA3.1 and pcDNA-GFAP (GFAP; cat. no. KR712259.1) were obtained from Shanghai GenePharma Co., Ltd. All $0.2 \mu \mathrm{g}$ fragments and $0.5 \mu$ loligos were transfected into $\mathrm{Mg}^{2+}$-induced epilepsy cells $\left(2 \times 10^{5}\right.$ cells/well) using Lipofectamine ${ }^{\circledR} 2000$ (Invitrogen; Thermo Fisher Scientific, Inc.), followed by incubation for $48 \mathrm{~h}$.

Reverse transcription-quantitative PCR (RT-qPCR). Total RNA was extracted from the hippocampal neural tissue or cells using TRIzol ${ }^{\circledR}$ reagent (Invitrogen; Thermo Fisher Scientific, Inc.) according to the manufacturer's protocol. Total RNA [for GFAP, interleukin (IL)-1 $\beta$, IL-6 and tumor necrosis factor $\alpha$ $($ TNF- $\alpha$ )] was reverse transcribed into cDNA using the High 
Capacity cDNA RT kit (Applied Biosystems; Thermo Fisher Scientific, Inc.), according to the manufacturer's protocol. TaqMan ${ }^{\circledR}$ miR RT PCR assay reagents (Applied Biosystems; Thermo Fisher Scientific, Inc.) was applied to synthesize cDNA first strands, and SYBR Green PCR kit (Takara Bio, Inc.) was used to determine the expression levels of miR-15a. The amplification parameters were: Initial denaturation at $95^{\circ} \mathrm{C}$ for $10 \mathrm{~min}$, followed by 40 cycles of denaturation at $95^{\circ} \mathrm{C}$ for $30 \mathrm{sec}$, annealing at $60^{\circ} \mathrm{C}$ for $30 \mathrm{sec}$ and extension at $72^{\circ} \mathrm{C}$ for $1 \mathrm{~min}$. GAPDH and U6 were used as the internal reference genes for mRNA and miRNA, respectively. Expression levels of all mRNAs and miRNA were calculated using the $2^{-\Delta \Delta C q}$ method (34). The primer sequences used are as follows: miR-15a forward, 5'-GTCGTATCCAGTGCAGGG TCCGAGGTATTCGCACTGGATACGACCACAAAC-3' and reverse, 5'-GCGGCTAGCAGCACATAATGG-3'; U6 forward, 5'-GCTTCGGCAGCACATATACTAAAAT-3' and reverse, 5'-CGCTTCACGAATTTGCGTGTCAT-3'; GFAP forward, 5'-TTGCACTGTGCACGTTC-3' and reverse, 5'-TGGGGA AATGTGCCAG-3'; GAPDH forward, 5'-GCACCGTCAAGG CTGAGAAC-3' and reverse, 5'-TGGTGAAGACGCCAGTGG A-3'; TNF- $\alpha$ forward, 5'-TCAGCCGATTTGCCATTTCAT-3' and reverse, 5'-ACACGCCAGTCGCTTCACAGA-3'; IL-1 $\beta$ forward, 5'-GTCCTTTCACTTGCCCTCAT-3' and reverse, 5'-CAAACTGGTCACAGCTTTCGA-3'; and IL-6 forward, 5'-AAATGCCTCGTGCTGTCTGACC-3' and reverse, 5'-GGT GGGTGTGCCGTCTTTCATC-3'.

TUNEL assay. Cell apoptosis was detected using TUNEL assay with a Fluorescein FragELTMDNA fragmentation detection kit (Abcam) according to the manufacturer's instructions. Briefly, cells fixed in 4\% paraformaldehyde (Beyotime Institute of Biotechnology) for $25 \mathrm{~min}$ at $4^{\circ} \mathrm{C}$ on the slides. After the sections (thickness, $5 \mu \mathrm{m}$ ) from rat tissues were washed with $\mathrm{H}_{2} \mathrm{O}_{2}$ and PBS, $20 \mathrm{mg} / \mathrm{l}$ protease $\mathrm{K}$ solution was added at room temperature for $15 \mathrm{~min}$. Then, $40 \mu \mathrm{l}$ stop buffer containing $20 \%$ FBS and $2 \mu \mathrm{l}$ nucleoside was added and the sections were incubated at $37^{\circ} \mathrm{C}$ for $1 \mathrm{~h}$. At $10 \mathrm{~min}$ post-addition of the stop buffer, peroxidase-conjugated anti-digoxin antibody (1:1,000; cat. no. ab53510; Abcam) was added and incubated at $37^{\circ} \mathrm{C}$ for $30 \mathrm{~min}$. After washing with PBS, the sections were re-stained with $0.1 \%$ hematoxylin for $3 \mathrm{~min}$ at room temperature. In total, six non-overlapping fields of view were selected randomly from each section, and apoptotic cells were observed and counted using a fluorescent microscope (magnification, x200).

Flow cytometric analysis of apoptosis. An Annexin (An)-VFITC apoptosis detection kit (BD Biosciences) was used to detect the levels of cell apoptosis. Cells $\left(1 \times 10^{5}\right)$ were collected and digested with trypsin, washed twice in PBS and centrifuged at $1,610 \mathrm{xg}$ for $8 \mathrm{~min}$ at $37^{\circ} \mathrm{C}$ to remove the supernatant. Subsequently, cells were resuspended in $100 \mu 1$ binding buffer from the detection kit, and stained with $5 \mu \mathrm{l}$ Annexin V/FITC and $5 \mu \mathrm{l}$ propidium iodide at room temperature for $15 \mathrm{~min}$ in the dark. Apoptotic cells were subsequently analyzed using a FACSCalibur flow cytometer (BD Biosciences) and CELL Quest 3.0 software (BD Biosciences). In the scatter plot of cell apoptosis: Lower left quadrant represented normal cells $\left(\mathrm{An}^{-} \mathrm{PI}^{-}\right)$; the lower right quadrant represented apoptotic cells in early stage $\left(\mathrm{An}^{+} \mathrm{PI}\right)$; the upper right quadrant represented apoptotic cells in advanced stage and necrotic cells $\left(\mathrm{An}^{+} \mathrm{PI}^{+}\right)$; and the upper left quadrant represented damaged cells in the process of collection $\left(\mathrm{An}^{-} \mathrm{PI}^{+}\right)$. The rate of apoptosis was expressed as the percentage of the early apoptotic cells in the total number of cells.

Dual-luciferase reporter assay. The underlying binding relationship between miR-15a and GFAP was predicted using bioinformatics software microT-CDS v5.0 (http://diana.imis. athena-innovation. gr/Diana Tools/index.php? $r=$ microT CDS/).

Then, a dual-luciferase reporter assay was used to determine the relationship between miR-15a and GFAP. The GFAP 3' untranslated region (UTR)-wild-type (WT) or GFAP 3'UTR-mutant (MUT) were amplified and inserted into the pRL-TK plasmid (Promega Corporation). Then, the vectors $(0.1 \mu \mathrm{g})$ and miR-15a $(40 \mathrm{nM})$ or miR-NC $(40 \mathrm{nM})$ were infected into hippocampal neurons using Lipofectamine 2000 (Invitrogen; Thermo Fisher Scientific, Inc.) according to the manufacturer's instructions. The relative luciferase activity was measured at $48 \mathrm{~h}$ post-transfection using the Dual-Luciferase Reporter assay system (Promega Corporation). Renilla luciferase activities were used as the internal control for the normalization of firefly luciferase activity.

RIP assay. The Magna RNA-binding protein immunoprecipitation kit (EMD Millipore) was used for the RIP experiment according to the manufacturer's protocol. Briefly, cells transfected with miR-15a were collected by centrifugation $(100 \mathrm{x} \mathrm{g})$ at room temperature for $2 \mathrm{~min}$ and resuspended in NP-40 lysis buffer (Sigma-Aldrich; Merck KGaA; reagent to separate the nuclei) containing $1 \mathrm{mM} \mathrm{PMSF}, 1 \mathrm{mM}$ DTT, $1 \%$ protease inhibitor cocktail and $200 \mathrm{U} / \mathrm{ml} \mathrm{R}$ Nase inhibitor (Invitrogen; Thermo Fisher Scientific, Inc.). Then, the supernatant was incubated $4^{\circ} \mathrm{C}$ with magnetic beads labelled with human anti-Argonaute2 (Ago2, 1:1,000; cat. no. ab32381; Abcam) antibody and IgG antibody (1:5,000; cat. no. PP64B, EMD Millipore) as a positive control overnight, sonicated for 10 cycles in a Bioruptor Sonicator [Diagenode; High, $10 \times(30 \mathrm{sec}-\mathrm{ON} / 30 \mathrm{sec}-\mathrm{OFF})]$ at $4^{\circ} \mathrm{C}$ and centrifuged $(6,000 \times \mathrm{g})$ at $4^{\circ} \mathrm{C}$ for $40 \mathrm{~min}$. The beads were washed three times with buffer containing $20 \mathrm{mM}$ HEPES (pH 7.9), $120 \mathrm{mM} \mathrm{NaCl}, 1 \mathrm{mM}$ EDTA, $1 \mathrm{mM}$ PMSF and $1 \mathrm{mM}$ DTT followed by centrifugation $(10,000 \mathrm{x} \mathrm{g} ; 40 \mathrm{~min}$; $\left.4^{\circ} \mathrm{C}\right)$. RNAs were digested with proteinase $\mathrm{K}(0.5 \mathrm{mg} / \mathrm{ml}$; Sigma-Aldrich; Merck $\mathrm{KGaA}$ ) for $15 \mathrm{~min}$ at $55^{\circ} \mathrm{C}$, and then treated with TRIzol ${ }^{\circledast}$ reagent (Invitrogen; Thermo Fisher Scientific, Inc.). The expression levels of miR-15a and GFAP were analyzed using RT-qPCR.

Western blot assay. Western blotting was used to detect the protein expression levels of GFAP in hippocampal neurons. Cells were lysed in RIPA lysis buffer (Beyotime Institute of Biotechnology).Protein concentration and quality were detected with a bicinchoninic acid protein assay kit (Sigma-Aldrich; Merck KGaA). Protein $(50 \mu \mathrm{g})$ samples were separated by $10 \%$ SDS-PAGE gels and then transferred onto PVDF membranes (Bio-Rad Laboratories, Inc.). Subsequently, 5\% skim milk for $2 \mathrm{~h}$ at $37^{\circ} \mathrm{C}$ was used to block the membranes. Then, the membranes were incubated with primary antibodies against 
GFAP (1:1,000; cat. no. ab7260; Abcam) or $\beta$-actin $(1: 2,500$; cat. no. ab52614; Abcam) at $4^{\circ} \mathrm{C}$ overnight. After washing with TBS, the membranes were incubated at $37^{\circ} \mathrm{C}$ with horseradish peroxidase-conjugated goat anti-rabbit secondary antibody (1:5,000; cat. no. SC-2301, Santa Cruz Biotechnology, Inc.) for $1 \mathrm{~h}$. The band of target protein was visualized using an ECL Plus western blotting substrate (Thermo Fisher Scientific, Inc.) and analyzed with Quantity One v4.6.2 software (Bio-Rad Laboratories, Inc.).

Statistical analysis. All statistical analyses and mapping were performed using GraphPad Prism 7.0 (GraphPad Software, Inc.). Statistical differences between two groups were determined using a paired and unpaired Student's t-test, whereas an one-way ANOVA with Tukey's test was used for $\geq 3$ groups. Data are presented as the mean \pm SD from $\geq 3$ independent experiments. $\mathrm{P}<0.05$ was considered to indicate a statistically significant difference.

\section{Results}

miR-15a expression levels are downregulated in TLE and epilepsy tissues. In the present study, healthy tissues and TLE tissues were obtained from 18 patients. In addition, healthy tissues and epileptic model rat tissues were collected from eight rats. RT-qPCR was performed to detect the expression levels of miR-15a and it was revealed that compared with the control tissues, the expression levels of miR-15a were significantly downregulated in the TLE tissues (Fig. 1A). Furthermore, miR-15a expression levels were significantly decreased in the epilepsy group compared with the normal group (Fig. 1B).

Overexpression of miR-15a inhibits cell apoptosis and inflammation in an in vivo epilepsy model. The transfection efficiency of LV-miR-15a in the hippocampal neurons was determined (Fig. 2A). Moreover, to determine the function of miR-15a, the present study transfected LV-miR-NC or LV-miR-15a into the hippocampi to construct the epilepsy + LV-miR-NC or epilepsy + LV-miR-15a groups, respectively. It was demonstrated that miR-15a expression levels were downregulated in the epilepsy group compared with the normal group, and miR-15a expression was enhanced in epilepsy + LV-miR-15a group compared with the epilepsy group (Fig. 2B). In addition, miR-15a expression levels were significantly increased in the epilepsy + LV-miR-15a group compared with the epilepsy $+\mathrm{LV}$-miR-NC group. The levels of cell apoptosis and expression levels of inflammatory factors were subsequently analyzed in each group using a TUNEL assay and RT-qPCR, respectively. The results demonstrated that the expression levels of IL-1 $\beta$, IL- 6 and TNF- $\alpha$, which are important pro-inflammatory factors (35), were upregulated in the epilepsy group vs. normal group, suggesting that there may be a strong inflammatory response in the epilepsy model. Moreover, the inflammatory factors were decreased in epilepsy + LV-miR-15a group compared with epilepsy group, suggesting that LV-miR-15a could inhibited inflammatory response in epilepsy model (Fig. 2D-F). Compared with the normal group, the levels of cell apoptosis were also significantly increased in the epilepsy group, and compared with the epilepsy group, cell apoptosis index was reduced in epilepsy + LV-miR-15a group (Fig. 2C). However, in the epilepsy + LV-miR-15a group, the levels of cell apoptosis were decreased, and the mRNA expression levels of IL-1 $\beta$, IL-6 and TNF- $\alpha$ were downregulated compared with the epilepsy + LV-miR-NC group (Fig. 2C-F). Therefore, these findings indicated that there were significant differences between the epilepsy and epilepsy + LV-miR-15a groups, implying that the upregulated expression levels of miR-15a may decrease the levels of cell apoptosis and inflammation in epilepsy tissues.

Overexpression of miR-15a inhibits cell apoptosis and inflammation in an in vitro epilepsy model. The overexpression transfection efficiency of miR-15a in hippocampal neurons was determined (Fig. 3A). Subsequently, the epileptic activity was induced in rat hippocampal neurons in vitro, which were divided into four groups: Con, $\mathrm{Mg}^{2+}$-free, $\mathrm{Mg}^{2+}$-free + miR-NC and $\mathrm{Mg}^{2+}$-free + miR-15a groups. The apoptotic rate and mRNA expression levels of inflammatory factors were analyzed for each group. Consistent with the in vivo experiments, it was identified that the expression levels of miR-15a were significantly downregulated in the $\mathrm{Mg}^{2+}$-free-treated cells compared with the control cells, while the expression levels of miR-15a were significantly increased in $\mathrm{Mg}^{2+}$-free + miR-15a group compared with the $\mathrm{Mg}^{2+}$-free + miR-NC group (Fig. 3B). Moreover, in the epileptic cells, the apoptotic rate was significantly increased, and the expression levels of IL-1 $\beta$, IL- 6 and TNF- $\alpha$ were significantly upregulated in $\mathrm{Mg}^{2+}$-free group compared with the con group (Fig. 3C-F). However, increasing the expression levels of miR-15a significantly reduced the high apoptotic rate and strong inflammatory response observed in the epileptic cells (Fig. 3C-F). Collectively, these results suggested that miR-15a may serve an important regulatory role in relieving the epileptic symptoms.

miR-15a directly targets GFAP in hippocampal neurons. Based on the prediction of the bioinformatics tool DIANA TOOLS, it was discovered that the 3 'untranslated region of GFAP had a complementary binding site to miR-15a (Fig. 4A). Therefore, it was hypothesized that GFAP may be a candidate target gene for miR-15a. The present study constructed vectors for GFAP-WT and GFAP-MUT, which were co-transfected alongside miR-NC and miR-15a into the hippocampal neurons. The dual-luciferase reporter assay results identified that miR-15a reduced the luciferase activity of GFAP-WT reporter, while it had no notable effect on luciferase activity of GFAP-MUT reporter (Fig. 4B). To further validate these results, a RIP assay was performed to detect the enrichment of GFAP in the cells. It was demonstrated that miR-15a and GFAP were co-immunoprecipitated using the Ago2 group antibody but not the IgG antibody (Fig. 4C). Subsequently, the transfection efficiency of miR-15a and anti-miR-15a was determined (Fig. 4D). The western blotting analysis revealed that the increased expression levels of miR-15a significantly inhibited the expression levels of GFAP compared with the miR-NC group; however, downregulating the expression levels of miR-15a significantly induced the expression of GFAP compared with anti-miR-NC group (Fig. 4E). Therefore, these 
A

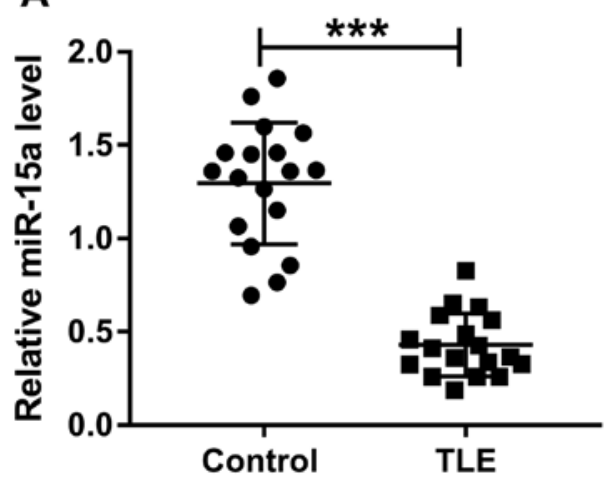

B

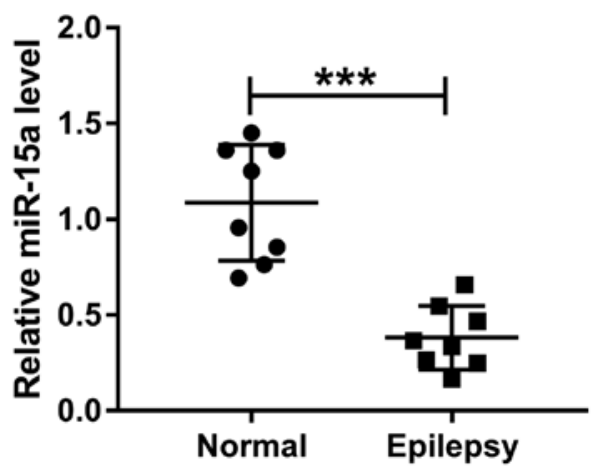

Figure 1. miR-15a expression levels are downregulated in TLE and epilepsy tissues. Expression levels of miR-15a were analyzed in the (A) control and TLE tissues or (B) normal and epilepsy hippocampal neurons using reverse transcription-quantitative PCR. ${ }^{* * *} \mathrm{P}<0.001$. TLE, temporal lobe epilepsy; miR, microRNA.
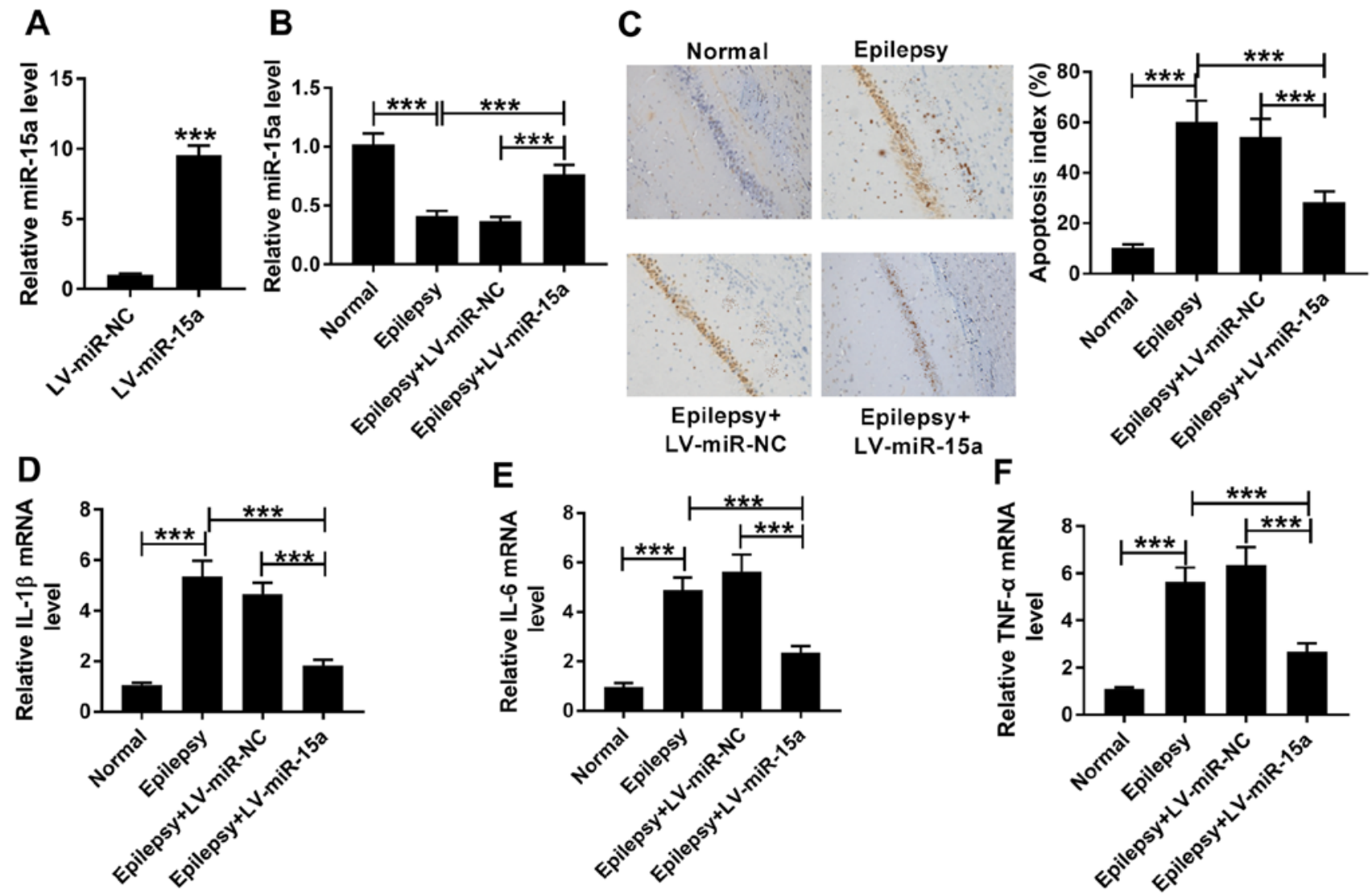

Figure 2. Overexpression of miR-15a inhibits cell apoptosis and inflammation in an in vivo epilepsy model. (A) miR-15a expression levels were detected in the hippocampal neurons transfected with the LV-miR-NC or LV-miR-15a using RT-qPCR. (B) Expression levels of miR-15a were analyzed in the normal, epilepsy, epilepsy + LV-miR-NC group and epilepsy + LV-miR-15a groups using RT-qPCR. (C) Levels of cell apoptosis were determined in the normal, epilepsy, epilepsy + LV-miR-NC and epilepsy + LV-miR-15a groups using a TUNEL assay (magnification, $x 200$ ). Expression levels of (D) IL-1 3 , (E) IL-6 and (F) TNF- $\alpha$ were analyzed in the normal, epilepsy, epilepsy + LV-miR-NC and epilepsy + LV-miR-15a groups using RT-qPCR. ${ }^{* * *}$ P $<0.001$. RT-qPCR, reverse transcription-quantitative PCR; miR, microRNA; NC, negative control; IL, interleukin; TNF- $\alpha$, tumor necrosis factor $\alpha$.

findings indicated that GFAP may be a target gene of miR-15a in hippocampal neurons.

Upregulation of GFAP reverses the effects of upregulated miR-15a expression-levels in an in vitro epilepsy model. In order to determine whether miR-15a regulated epilepsy by targeting GFAP, rescue experiments were performed. The western blotting results demonstrated that the expression levels of GFAP were significantly upregulated in the hippocampal neurons transfected with GFAP compared with cells transfected with pcDNA3.1 (Fig. 5A). miR-NC or miR-15a were transfected into $\mathrm{Mg}^{2+}$-free-induced hippocampal neurons, with or without the co-transfection with pcDNA3.1 and GFAP. It was subsequently demonstrated that the protein expression levels of GFAP were significantly upregulated in the $\mathrm{Mg}^{2+}$-free group compared with the con group (Fig. 5B). Moreover, the overexpression of 
A

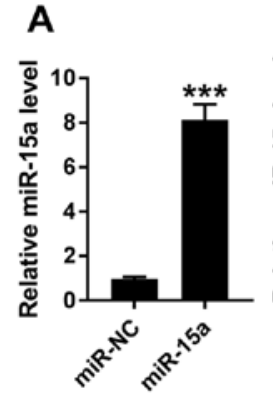

B

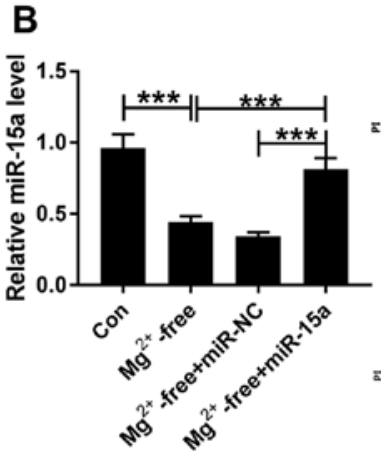

C con

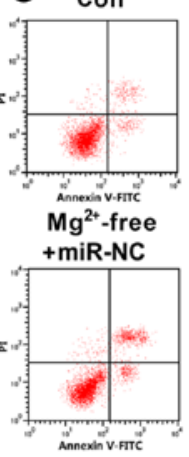

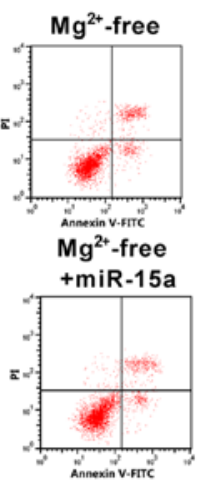

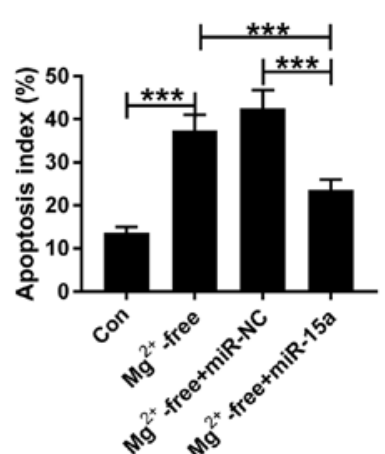

D

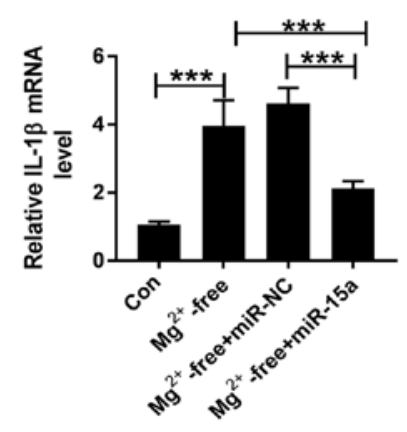

E

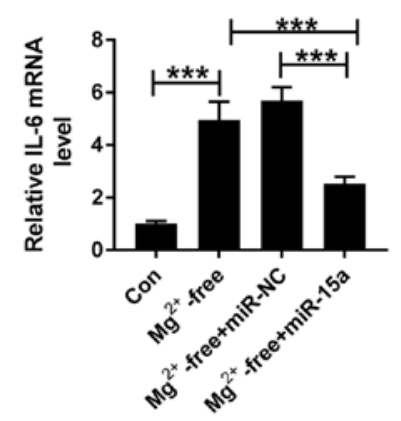

F

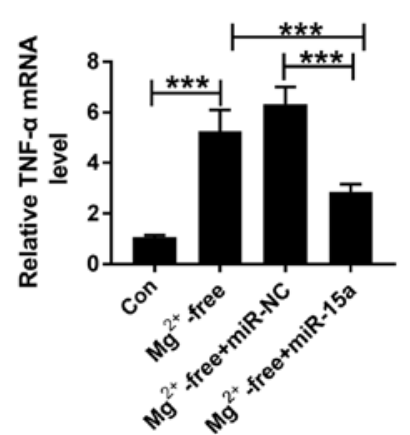

Figure 3. Overexpression of miR-15a inhibits cell apoptosis and inflammation in an in vitro epilepsy model. (A) RT-qPCR was used to analyze the expression levels of miR-15a in hippocampal neurons transfected with miR-NC or miR-15a. (B) Expression levels of miR-15a wereanalyzed in the con, Mg ${ }^{2+}$-free, $\mathrm{Mg}^{2+}$-free + miR-NC and $\mathrm{Mg}^{2+}$-free+miR-15a groups via RT-qPCR. (C) Levels of cell apoptosis were analyzed in the con, $\mathrm{Mg}^{2+}$-free, $\mathrm{Mg}^{2+}-$ free + miR-NC and $\mathrm{Mg}^{2+}$-free + miR-15a groups using flow cytometry. Expression levels of (D) IL-1 $\beta$, (E) IL-6 and (F) TNF- $\alpha$ were determined in the con, $\mathrm{Mg}^{2+}$-free, $\mathrm{Mg}^{2+}-$ free + miR-NC and $\mathrm{Mg}^{2+}$-free + miR-15a groups using RT-qPCR. ${ }^{* * *} \mathrm{P}<0.001$. RT-qPCR, reverse transcription-quantitative PCR; miR, microRNA; NC, negative control; IL, interleukin; TNF- $\alpha$, tumor necrosis factor $\alpha$; con, control; PI, propidium iodide.

A

Position : chr10:92060896-92060908 of GFAP 3'UTR

GFAP-WT

rno-miR-15a

5'... GaguUUucauaggcugcug....3'

|| |||

3'UUUGGUAAUACACG ACG AU 5'

GFAP-MUT $\quad 5$ '... GAGUUUUCAUAGAUGUUCG...3'

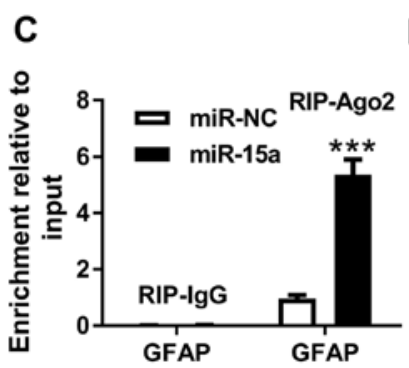

D
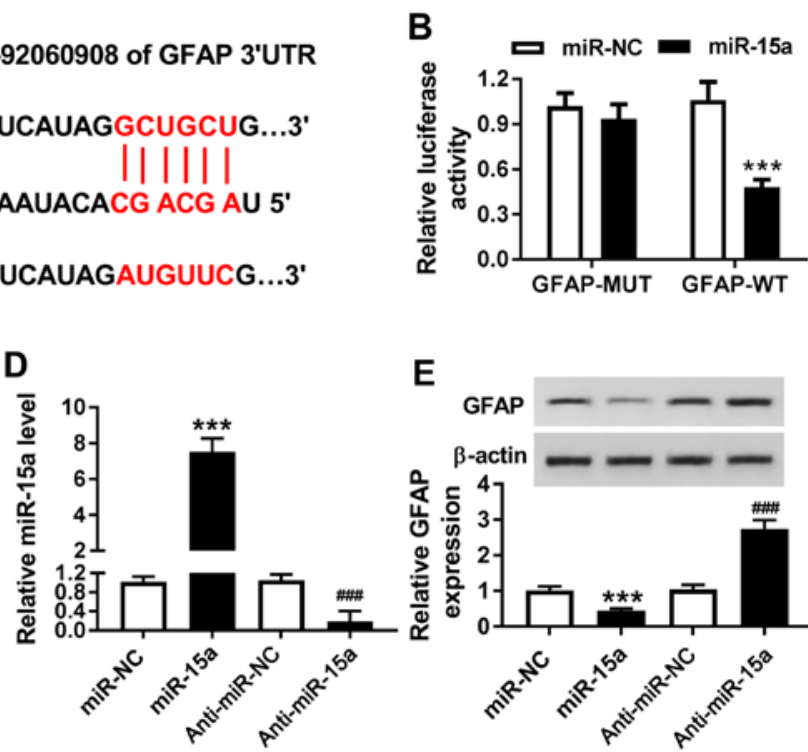

E

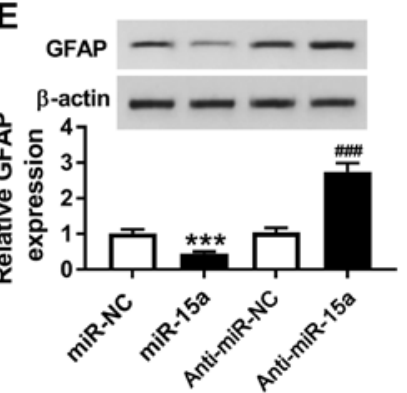

Figure 4. miR-15a directly targets GFAP in hippocampal neurons. (A) Schematic representation of the predicted target site for miR-15a in the GFAP 3'UTR. (B) Dual-luciferase reporter assay was performed to determine the target relationship between miR-15a and GFAP. (C) RIP assay was performed to further identify the relationship between miR-15a and GFAP in hippocampal neurons. (D) Expression levels of miR-15a were analyzed in the hippocampal neurons transfected with miR-NC, miR-15a, anti-miR-NC and anti-miR-15a. (E) Protein expression levels of GFAP were analyzed in miR-NC, miR-15a, anti-miR-NC and anti-miR-15a groups using western blotting. ${ }^{* * *} \mathrm{P}<0.001$ vs. miR-NC; ${ }^{\# \#} \mathrm{P}<0.001$ vs. anti-miR-NC. 3'UTR, 3'untranslated region; miR, microRNA; NC, negative control; GFAP, glial fibrillary acidic protein; WT, wild-type; MUT, mutant; Ago2, Argonaute2; RIP, RNA immunoprecipitation.

miR-15a significantly inhibited the expression levels of GFAP in $\mathrm{Mg}^{2+}$-free + miR-15a group compared with the $\mathrm{Mg}^{2+}$-free
+ miR-NC group, while upregulating the expression levels of GFAP reversed this inhibitory effect. In addition, the results 
A
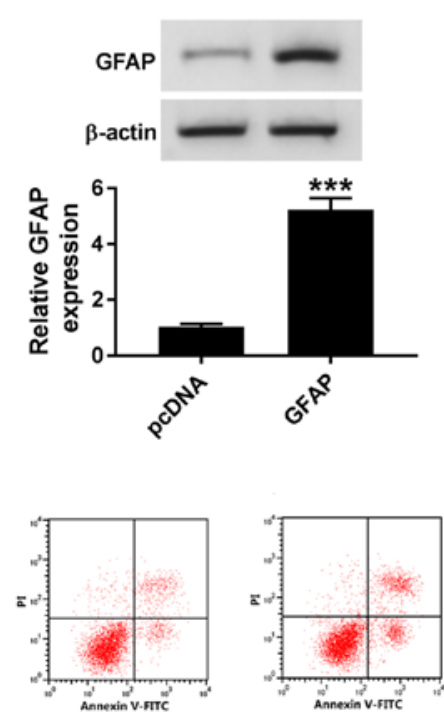

con

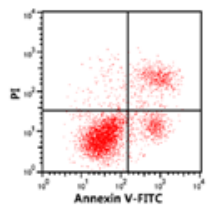

Mg2+-free

D

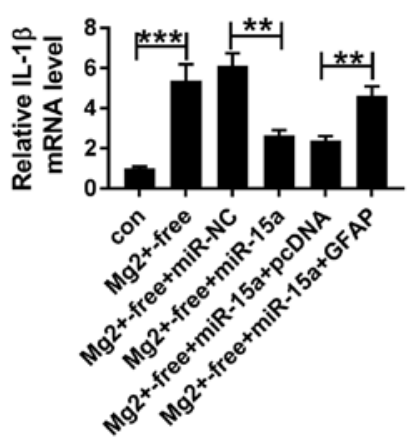

B
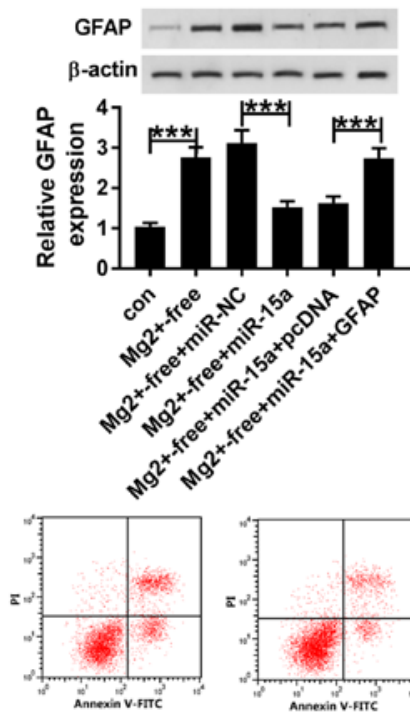

Mg2+-free + miR-NC

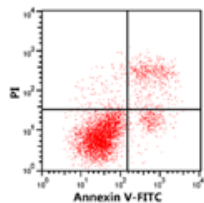

Mg2+-free + miR-15a

E

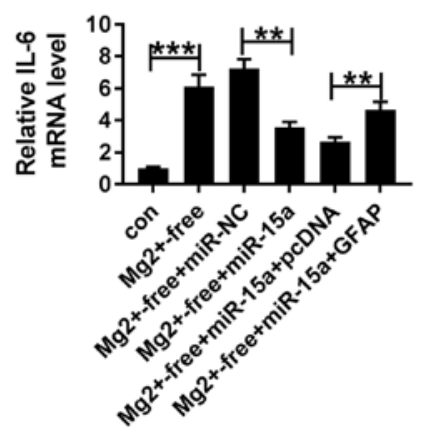

C
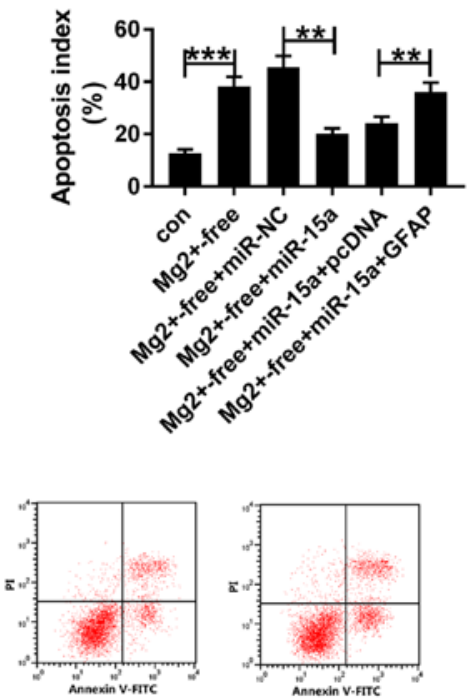

Mg2+-free+miR Mg2+-free+miR $-15 a+$ pcDNA $-15 a+$ GFAP

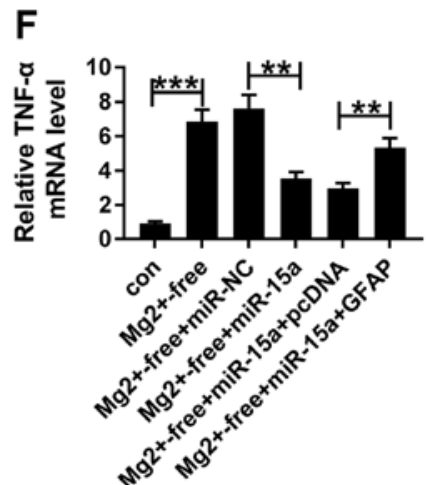

Figure 5. Upregulation of GFAP reverses the effects of upregulated miR-15a expression levels on cell apoptosis and inflammation in an in vitro epilepsy model. (A) GFAP protein expression levels were determined in hippocampal neurons transfected with pcDNA and GFAP. (B) Protein expression levels of GFAP were analyzed in the con, $\mathrm{Mg}^{2+}$-free, $\mathrm{Mg}^{2+}$-free + miR-NC, $\mathrm{Mg}^{2+}$-free + miR-15a, $\mathrm{Mg}^{2+}$-free + miR-15a + pcDNA and Mg ${ }^{2+}$-free + miR-15a + GFAP groups using western blotting. (C) Levels of cell apoptosis were examined in the con, $\mathrm{Mg}^{2+}$-free, $\mathrm{Mg}^{2+}$-free $+\mathrm{miR}-\mathrm{NC}, \mathrm{Mg}^{2+}-$ free $+\mathrm{miR}-15 \mathrm{a}, \mathrm{Mg}^{2+}-$ free $+\mathrm{miR}-15 \mathrm{a}+\mathrm{pcDNA}$ and $\mathrm{Mg}^{2+}$-free + miR-15a + GFAP groups using flow cytometry. Expression levels of (D) IL-1 $\beta$, (E) IL- 6 and (F) TNF- $\alpha$ were detected in the con, Mg ${ }^{2+}$-free, $\mathrm{Mg}^{2+}$-free + miR-NC, $\mathrm{Mg}^{2+}$-free + miR-15a, $\mathrm{Mg}^{2+}$-free + miR-15a + pcDNA and $\mathrm{Mg}^{2+}$-free + miR-15a + GFAP groups using reverse transcription-quantitative PCR. ${ }^{* *} \mathrm{P}<0.01,{ }^{* * *} \mathrm{P}<0.001$. miR, microRNA; NC, negative control; IL, interleukin; TNF- $\alpha$, tumor necrosis factor $\alpha$; GFAP, glial fibrillary acidic protein; con, control; PI, propidium iodide.

identified that the apoptotic rate in the $\mathrm{Mg}^{2+}$-free group was increased compared with the con group (Fig. 5C). Furthermore, the upregulation of GFAP reversed the miR-15a overexpression-mediated decrease in the levels of cell apoptosis (Fig. 5C). It was also discovered that the expression levels of IL-1 $\beta$, IL-6 and TNF- $\alpha$ were upregulated in the $\mathrm{Mg}^{2+}$-free group compared with the con group (Fig. 5D-F). Moreover, the overexpression of GFAP also partially reversed the suppressive effects of miR-15a on the expression levels of IL-1 $\beta$, IL- 6 and TNF- $\alpha$ in $\mathrm{Mg}^{2+}$-free-induced hippocampal neurons (Fig. 5D-F). Thus, the present results suggested that cell apoptosis and inflammation may be inhibited by the upregulation of miR-15a, which may be impaired by the overexpression of GFAP.

\section{Discussion}

The present study used a rat model of epilepsy and epilepsy-induced hippocampal neurons to study the pathogenesis of TLE. It was discovered that the expression levels of miR-15a were downregulated in the epileptic tissue and TLE tissues. Furthermore, increasing the expression levels of miR-15a effectively inhibited GFAP expression, which in turn affected the levels of neuronal apoptosis and inflammation. Therefore, the present results indicated that the miR-15a/GFAP axis may be an important regulatory mechanism and network in epilepsy, thus providing a novel target site for the treatment of epilepsy.

miRNAs serve important regulatory roles in numerous types of disease and they are indispensable regulators of cell development and inflammation (36-39). In cancer, miRNAs have been discovered to serve as either a tumor suppressor or an oncogenic factor, where they were observed to have roles in cell development, such as tumorigenesis and metastasis (40-43). Moreover, numerous differentially expressed miRNAs have been found in epileptic sequencing, including miR-184, miR-124, miR-134, miR-132, miR-21 and miR-23a/b, where they were identified to be involved in the occurrence 
and development of epilepsy $(20,25,44,45)$. Previous studies have reported that miR-15a was involved in the development of several types of human disease, cancer, the immune response and angiogenesis (23,46-49). Furthermore, Cai et al (24) revealed that the overexpression of miR-15a induced cell apoptosis and the cell cycle in osteosarcoma. However, research on the role of miR-15a in epilepsy is limited. Thus, the present study investigated the function of miR-15a in vitro and in vivo, and it was revealed that the overexpression of miR-15a significantly inhibited the rate of apoptosis and inflammation in hippocampal neurons.

miRNAs typically target multiple mRNAs, including miR-15a $(24,50)$. Previous studies have revealed that cyclin D1, vascular endothelial growth factor A (VEGFA), forkhead box protein $\mathrm{O} 1$ (FOXO1), brain-derived neurotrophic factor (BDNF) and C-X-C motif chemokine 10 (CXCL10) were targets of miR-15a in osteosarcoma, porcine pre-adipocytes, methyl $\mathrm{CpG}$ binding protein 2-deficient neurons, myasthenia gravis and multiple myeloma (49,51-54). Notably, these regulatory networks were discovered to regulate cell progression and angiogenesis $(24,47,49,51,53,54)$. The results of the present study suggested that GFAP may be a target gene for miR-15a. Previous studies have revealed that GFAP encodes the GFAP protein, which was reported to be an important regulator in the formation and development of astrocytes $(55,56)$. Furthermore, GFAP has been observed to affect the inflammatory response in numerous types of disease. For example, Sun et al (57) reported that GFAP was related to the inflammatory response in the lumbo-sacral spinal cord and medulla oblongata after chronic colonic inflammation in rats. It has also been reported that GFAP was highly expressed in epilepsy, and elevated GFAP expression levels subsequently aggravated the neuroinflammatory response $(27,55)$. Consistent with these previous studies, the findings of the present study indicated that the increased expression levels of GFAP may inhibit the suppression of apoptosis and inflammation in hippocampal neurons induced by increased expression levels of miR-15a, thus suggesting the important role of the miR-15a/GFAP axis in TLE.

In conclusion, the present study identified the function of miR-15a in TLE and assessed the regulatory mechanism of miR-15a. It was discovered that the upregulation of miR-15a inhibited cell apoptosis and inflammation in TLE, which was impaired by the overexpression of GFAP. Therefore, the results of the present study may provide a novel therapeutic target for the treatment of TLE.

\section{Acknowledgements}

Not applicable.

\section{Funding}

No funding was received.

\section{Availability of data and materials}

The datasets used and/or analyzed during the current study are available from the corresponding author on reasonable request.

\section{Authors' contributions}

WW and WL designed and conceptualized the study; WL and XL analyzed and curated the data; YF and WL validated the data and performed the experiments; and YF, WW and WL wrote the original draft of the manuscript, and reviewed and analyzed the manuscript. All authors read and approved the final manuscript.

\section{Ethics approval and consent to participate}

The present study was approved by the Ethical Review Committee of The Second Hospital of Hebei Medical University (Shijiazhuang, China). Written informed consent was obtained from all enrolled patients.

\section{Patient consent for publication}

Not applicable.

\section{Competing interests}

The authors declare that they have no competing interests.

\section{References}

1. Kwan P and Brodie MJ: Early identification of refractory epilepsy. N Engl J Med 342: 314-319, 2000.

2. Roggenhofer E, Santarnecchi E, Muller S, Kherif F, Wiest R, Seeck $M$ and Draganski B: Trajectories of brain remodeling in temporal lobe epilepsy. J Neurol 266: 3150-3159, 2019.

3. Fiest KM, Sauro KM, Wiebe S, Patten SB, Kwon CS, Dykeman J, Pringsheim T, Lorenzetti DL and Jetté N: Prevalence and incidence of epilepsy: A systematic review and meta-analysis of international studies. Neurology 88: 296-303, 2017.

4. Engel J Jr; International League Against Epilepsy (ILAE): A proposed diagnostic scheme for people with epileptic seizures and with epilepsy: Report of the ILAE task force on classification and terminology. Epilepsia 42: 796-803, 2001.

5. Lowenstein DH: Interview: The national institute of neurological diseases and stroke/American epilepsy society benchmarks and research priorities for epilepsy research. Biomark Med 5: 531-535, 2011.

6. Beghi E: The epidemiology of epilepsy. Neuroepidemiology 54: 185-191, 2020.

7. Wahid F, Shehzad A, Khan T and Kim YY: MicroRNAs: Synthesis, mechanism, function, and recent clinical trials. Biochim Biophys Acta 1803: 1231-1243, 2010.

8. Witkos TM, Koscianska E and Krzyzosiak WJ: Practical aspects of microRNA target prediction. Curr Mol Med 11: 93-109, 2011.

9. Saito T and Saetrom P: MicroRNAs-targeting and target prediction. N Biotechnol 27: 243-249, 2010.

10. Cheng AM, Byrom M, Shelton J and Ford LP: Antisense inhibition of human miRNAs and indications for an involvement of miRNA in cell growth and apoptosis. Nucleic Acids Res 33: 1290-1297, 2005

11. Cloonan N, Wani S, Xu Q, Gu J, Lea K, Heater S, Barbacioru C, Steptoe AL, Martin HC, Nourbakhsh E, et al: MicroRNAs and their isomiRs function cooperatively to target common biological pathways. Genome Biol 12: R126, 2011.

12. Dar AA, Majid S, de Semir D, Nosrati M, Bezrookove V and Kashani-Sabet M: miRNA-205 suppresses melanoma cell proliferation and induces senescence via regulation of $\mathrm{E} 2 \mathrm{~F} 1$ protein. J Biol Chem 286: 16606-16614, 2011.

13. Kovaleva V, Mora R, Park YJ, Plass C, Chiramel AI, Bartenschlager R, Döhner H, Stilgenbauer S, Pscherer A, Lichter P and Seiffert M: miRNA-130a targets ATG2B and DICER1 to inhibit autophagy and trigger killing of chronic lymphocytic leukemia cells. Cancer Res 72: 1763-1772, 2012.

14. Mehta N and Cheng HY: Micro-managing the circadian clock: The role of microRNAs in biological timekeeping. J Mol Biol 425: 3609-3624, 2013. 
15. Bencurova P, Baloun J, Musilova K, Radova L, Tichy B, Pail M, Zeman M, Brichtova E, Hermanova M, Pospisilova S, et al: MicroRNA and mesial temporal lobe epilepsy with hippocampal sclerosis: Whole miRNome profiling of human hippocampus. Epilepsia 58: 1782-1793, 2017.

16. Dogini DB, Avansini SH, Vieira AS and Lopes-Cendes I: MicroRNA regulation and dysregulation in epilepsy. Front Cell Neurosci 7: 172, 2013

17. Liu DZ, Tian Y, Ander BP, Xu H, Stamova BS, Zhan X, Turner RJ, Jickling $\mathrm{G}$ and Sharp FR: Brain and blood microRNA expression profiling of ischemic stroke, intracerebral hemorrhage, and kainate seizures. J Cereb Blood Flow Metab 30: 92-101, 2010.

18. Mckiernan RC, Jimenez-Mateos EM, Bray I, Engel T, Brennan GP, Sano T, Michalak Z, Moran C, Delanty N, Farrell M, et al: Reduced mature microRNA levels in association with dicer loss in human temporal lobe epilepsy with hippocampal sclerosis. PLoS One 7: 35921, 2012.

19. Pitkanen A, Loscher W, Vezzani A, Becker AJ, Simonato M, Lukasiuk K, Gröhn O, Bankstahl JP, Friedman A, Aronica E, et al: Advances in the development of biomarkers for epilepsy. Lancet Neurol 15: 843-856, 2016

20. Song YJ, Tian XB, Zhang S, Zhang YX, Li X, Li D, Cheng Y, Zhang JN, Kang CS and Zhao W: Temporal lobe epilepsy induces differential expression of hippocampal miRNAs including let-7e and miR-23a/b. Brain Res 1387: 134-140, 2011.

21. Li D, Hao S and Zhang J: Long non-coding RNA UCA1 exerts growth modulation by miR-15a in human thyroid cancer TPC-1 cells. Artif Cells Nanomed Biotechnol 47: 1815-1822, 2019.

22. Cui Y, Yang Y, Ren L, Yang J, Wang B, Xing T, Chen $H$ and Chen M: miR-15a-3p suppresses prostate cancer cell proliferation and invasion by targeting SLC39A7 via downregulating Wnt $/ \beta$-catenin signaling pathway. Cancer Biother Radiopharm 34: 472-479, 2019.

23. Aqeilan RI, Calin GA and Croce CM: miR-15a and miR-16-1 in cancer: Discovery, function and future perspectives. Cell Death Differ 17: 215-220, 2010

24. Cai CK, Zhao GY, Tian LY, Liu L, Yan K, Ma YL, Ji ZW, Li XX Han K, Gao J, et al: miR-15a and miR-16-1 downregulate CCND1 and induce apoptosis and cell cycle arrest in osteosarcoma. Oncol Rep 28: 1764-1770, 2012

25. Wang J, Yu JT, Tan L, Tian Y, Ma J, Tan CC, Wang HF, Liu Y, Tan MS, Jiang T and Tan L: Genome-wide circulating microRNA expression profiling indicates biomarkers for epilepsy. Sci Rep 5: 9522, 2015.

26. Ma Y: The Challenge of microRNA as a biomarker of epilepsy. Curr Neuropharmacol 16: 37-42, 2018.

27. Jacque CM, Vinner C, Kujas M, Raoul M, Racadot $\mathbf{J}$ and Baumann NA: Determination of glial fibrillary acidic protein (GFAP) in human brain tumors. J Neurol Sci 35: 147-155, 1978.

28. Venkatesh K, Srikanth L, Vengamma B, Chandrasekhar C, Sanjeevkumar A, Mouleshwara Prasad BC and Sarma PV: In vitro differentiation of cultured human $\mathrm{CD} 34^{+}$cells into astrocytes. Neurol India 61: 383-388, 2013.

29. Hol EM and Pekny M: Glial fibrillary acidic protein (GFAP) and the astrocyte intermediate filament system in diseases of the central nervous system. Curr Opin Cell Biol 32: 121-130, 2015.

30. Storoni M, Verbeek MM, Illes Z, Marignier R, Teunissen CE, Grabowska M, Confavreux C, Plant GT and Petzold A: Serum GFAP levels in optic neuropathies. J Neurol Sci 317: 117-122, 2012.

31. Zhao T, Ding Y, Li M, Zhou C and Lin W: Silencing lncRNA PVT1 inhibits activation of astrocytes and increases BDNF expression in hippocampus tissues of rats with epilepsy by downregulating the Wnt signaling pathway. J Cell Physiol, Feb 25, 2019 (Epub ahead of print).

32. Ahmadian SR, Ghasemi-Kasman M, Pouramir M and Sadeghi F: Arbutin attenuates cognitive impairment and inflammatory response in pentylenetetrazol-induced kindling model of epilepsy. Neuropharmacology 146: 117-127, 2019.

33. Huang LG, Zou J and Lu QC: Silencing rno-miR-155-5p in rat temporal lobe epilepsy model reduces pathophysiological features and cell apoptosis by activating Sestrin-3. Brain Res 1689: 109-122, 2018

34. Livak KJ and Schmittgen TD: Analysis of relative gene expression data using real-time quantitative PCR and the 2(-Delta Delta C(T)) method. Methods 25: 402-408, 2001.

35. Ng A, Tam WW, Zhang M, Ho CS, Husain SF, McIntyre RS and Ho RC: IL-1 $\beta$, IL-6, TNF- $\alpha$ and CRP in elderly patients with depression or Alzheimer's disease: Systematic review and meta-analysis. Sci Rep 8: 12050, 2018.
36. Li Y and Kowdley KV: MicroRNAs in common human diseases. Genomics Proteomics Bioinformatics 10: 246-253, 2012.

37. Iborra M, Bernuzzi F, Invernizzi P and Danese S: MicroRNA in autoimmunity and inflammatory bowel disease: Crucial regulators in immune response. Autoimmun Rev 11: 305-314, 2012.

38. Lei H, Tang J, Li H, Zhang H, Lu C, Chen H, Li W, Xia Y and Tang W: MiR-195 affects cell migration and cell proliferation by down-regulating DIEXF in Hirschsprung's disease. BMC Gastroenterol 14: 123, 2014.

39. Simpson LJ and Ansel KM: MicroRNA regulation of lymphocyte tolerance and autoimmunity. J Clin Invest 125: 2242-2249, 2015.

40. Zhang B, Pan X, Cobb GP and Anderson TA: microRNAs as oncogenes and tumor suppressors. Dev Biol 302: 1-12, 2007.

41. Hwang HW and Mendell JT: MicroRNAs in cell proliferation, cell death, and tumorigenesis. Br J Cancer 94: 776-780, 2006.

42. Heinzelmann J, Henning B, Sanjmyatav J, Posorski N, Steiner T, Wunderlich H, Gajda MR and Junker K: Specific miRNA signatures are associated with metastasis and poor prognosis in clear cell renal cell carcinoma. World J Urol 29: 367-373, 2011

43. Fu X, Meng Z, Liang W, Tian Y, Wang X, Han W, Lou G, Wang X, Lou F, Yen Y, et al: miR-26a enhances miRNA biogenesis by targeting Lin28B and Zcchc11 to suppress tumor growth and metastasis. Oncogene 33: 4296-4306, 2014

44. Danis B, Van Rikxoort M, Kretschmann A, Zhang J, Godard P, Andonovic L, Siegel F, Niehusmann P, Hanon E, Delev D, et al: Differential expression of miR-184 in temporal lobe epilepsy patients with and without hippocampal sclerosis-Influence on microglial function. Sci Rep 6: 33943, 2016.

45. Peng J, Omran A, Ashhab MU, Kong H, Gan N, He F and Yin F: Expression patterns of miR-124, miR-134, miR-132, and miR-21 in an immature rat model and children with mesial temporal lobe epilepsy. J Mol Neurosci 50: 291-297, 2013.

46. Li Y, Zhang B, Li W, Wang L, Yan Z, Li H, Yao Y, Yao R, $\mathrm{Xu}$ K and Li Z: MiR-15a/16 regulates the growth of myeloma cells, angiogenesis and antitumor immunity by inhibiting Bcl-2, VEGF-A and IL-17 expression in multiple myeloma. Leuk Res 49: 73-79, 2016.

47. Chen $\mathrm{H}$ and Tian $\mathrm{Y}$ : MiR-15a-5p regulates viability and matrix degradation of human osteoarthritis chondrocytes via targeting VEGFA. Biosci Trends 10: 482-488, 2017.

48. Kang W, Tong JH, Lung RW, Dong Y, Zhao J, Liang Q, Zhang L, Pan Y, Yang W and Pang JC: Targeting of YAP1 by microRNA-15a and microRNA-16-1 exerts tumor suppressor function in gastric adenocarcinoma. Mol Cancer 14: 52, 2015.

49. Liu XF, Wang RQ, Hu B, Luo MC, Zeng QM, Zhou H, Huang K, Dong XH, Luo YB, Luo ZH and Yang H: MiR-15a contributes abnormal immune response in myasthenia gravis by targeting CXCL10. Clin Immunol 164: 106-113, 2016.

50. Fan B, Chen LP, Yuan YH, Xiao HN, Lv XS and Xia ZY: MiR-15a-3p suppresses the growth and metastasis of ovarian cancer cell by targeting twist1. Eur Rev Med Pharmacol Sci 23: 1934-1946, 2019

51. Lines KE, Newey PJ, Yates CJ, Stevenson M, Dyar R, Walls GV, Bowl MR and Thakker RV: MiR-15a/miR-16-1 expression inversely correlates with cyclin D1 levels in men1 pituitary NETs. J Endocrinol 240: 41-50, 2018.

52. Li YJ, Zhang BY, Li WJ, Wang LJ, Yan ZL, Li H, Yao Y, Yao R, $\mathrm{Xu}$ K and Li Z: MiR-15a/16 regulates the growth of myeloma cells angiogenesis and antitumor immunity by inhibiting Bcl-2, VEGF-A and IL-17 expression in multiple myeloma. Leuk Res 49: 73-79, 2016.

53. Dong P, Mai Y, Zhang Z, Mi L, Wu G, Chu G, Yang G and Sun S: $\mathrm{MiR}-15 \mathrm{a} / \mathrm{b}$ promote adipogenesis in porcine pre-adipocyte via repressing FoxO1. Acta Biochim Biophys Sin (Shanghai) 46: $565-571,2014$

54. Gao Y, Su J, Guo W, Polich ED, Magyar DP, Xing Y, Li H, Smrt RD, Chang $\mathrm{Q}$ and Zhao X: Inhibition of miR-15a promotes BDNF expression and rescues dendritic maturation deficits in MeCP2-Deficient neurons. Stem Cells 33: 1618-1629, 2015.

55. Isaacs $A$, Baker $M$, Wavrant-De Vrièze $F$ and Hutton $M$ : Determination of the gene structure of human GFAP and absence of coding region mutations associated with frontotemporal dementia with parkinsonism linked to chromosome 17 Genomics 51: 152-154, 1998

56. Reeves SA, Helman LJ, Allison A and Israel MA: Molecular cloning and primary structure of human glial fibrillary acidic protein. Proc Natl Acad Sci USA 86: 5178-5182, 1989

57. Sun YN, Luo JY, Rao ZR, Lan L and Duan L: GFAP and Fos immunoreactivity in lumbo-sacral spinal cord and medulla oblongata after chronic colonic inflammation in rats. World $\mathrm{J}$ Gastroenterol 11: 4827-4832, 2005. 